\title{
İşletme Ekonomisi Biliminin Ekonomi Bilimleri, Ekonomi Tatbikati ve Ekonomi Siyasetleriyle Olan Münasebetleri
}

\author{
Prof. Dr. Muhlis ETE
}

\author{
I. İ̧̧ettne Ekonomisi biliminin Ekoøomi bilimleri ile münasebeti \\ Il. İ̧letme Ekononisi bilimi ve Tathikî Ekonomi \\ IIl. İşletune Ekọnumisi ve Ekonomi Siyaseti \\ IV. İsletme Ekonomisi ve Htrkukeuya yararliğt
}

\section{İşletme ekonomisi bilimi :}

Bilim dilimize işletme ekonomisi adın vererek getirdiğimiz bu ilim şubesi, ekonomi ilimlerinin en genç bir disiplinidir. Aşağı yukarı 45 yaşındadır. Bu ilmin yabancı dillerdeki mukabilini bulmak pek kolay degrildir. Almanların Betriebswirtschaftslehre'lerine mukabil, Anglo-Saksonlarn «Business'Economics veya Business Administration" tabirlerl, Fransızların, "Organisation et Exploitation des Entreprises", Italyanların "Economi Aziendale" tabirleri bu ilmi ifadeye çalışmışlardır.

İşletme ekonomisi bilhassa içinde yaşadı̆̆ımı asrm başiangıcindanberi hemen bütün kültür memleketlerinde taammüm etmiş ve ekonomi ilimleri arasinda hususî bir önem kazanmıştır.

Bugün muhtelif memleketlerin hususî Universite ve Yüksek okullarında "Ișletme Ekonomisi" ilmini tedris eden profesörlerin sayısı 500 ü geçmiştir.

Bugün işletme ekonomisi o kadar kıymet kesbetmiştir ki, iktisadî nazariyat, tatbikat ve siyaset ile meşgui olan fertier veya müesseseler bu ilimle ünsiyet peyda etmeden :müstağni kalamiyorlar. 


\section{İ̧letme ekonomisi biliminin özellik arzettiç memleketler:}

Arzettikleri hacim itibariyle muhtelif memleketlerde karşlaştıそ̆ımı işletme ekonomisi literatürünü bilhassa şu 4 grup altında toplamak mümkündür;

1 - Anglo-Sakson literatürü,

2 - Alman literatürü,

3 - Italyan literatürü,

4 - Japon literatürü.

Ingiliz - Amerikan literatürü : Hacim ve ihtiva ettiŏi münferit hahisler itibariyle bir hususiyet arzetmektedir. (Muhasebe, bilânço, masraf, sürüm ve mürakabe mevzuları);

Alman literatürüa : Daha organik bir sistem, daha derli toplu bir fikir silsilesi arzetmekle temayüz etmiștir.

Italyan literatürü : Eskiliği, hạcmi ve orij̣inalitesi bakımından önem kazanmıştır.

Japon literatürü : Avrupanın muhtelif memleketlerinden mülhem olan zengin ve modern bir literatür arzetmektedir.

Diğer memleketlerin işletme ekonomisi literatürü bu dört grup memleket literatüründen az çok mülhem olmuştur,

\section{Işletme ekonomisi ilminin gelişim tarłhi :}

Işletme ekonomisinin bugünkü mevzuunu teşkil eden bazi malzemesinin menşei çok eski devirlerde yazılmı̣s bazı eserlerden gelmiştir.

Xenophon ve Aristotel'in «Oikonomia" ev idarelerine dair yazdıkları eserlerde ve eski Romanın ziraat işletme usullerine dair yazılarında işletme ekonomisinin izlerini görmek mümkün olabilir.

Orta devirlerde Avrupada yazlan kitaplara geçmeden evvel 1174 senesinde Şamda $A l$. Dimisqui tarafundan rTicarî Bilgilere» yazilan bir kitapta :Tüccara ve ticarete, sermaye ve tediye işlerine* dair yazılmış enteresan bahislere tesadüf edilmiş̧tir. Bu kitap 1900 de Kahire'de basilmıştir [1].

[1] Işletme meemuası No. 1, sayfa, 6. 
14 üncü ve 15 inci yüzylda işletme ekonomisine ilk malzeme verebilecek yazllara tesadüf etmektedir. 1494 de İtalyan rahibi Sheoloji ve Mathematik profesörü olan Luca Pacioli'nin ilk basılmış kitabı intişar etmiştir. Muzaaf usulü muhasebenin mekanizmasından bahseden bu eser uzun zaman bir çok Alman muhasebe kilaplarına mehez teşkil etmiştir.

1675 senesinde Fransiz Jaques Savary'nin Le parfait négociant adh kitabı intişar elmiş ve büyük bir tesir yapmıştır. 1.68 de Almanya'da Leipzig Üniversitesi profesörlerinden Ludovic:'nin "Tam bir ticaret sisteminin ana hatları kitabı intişar etmiştir.

Almanya'da : Işletme ekonomisi biliminin asıl geliştiği memleket Almanyadır. Betriebswirtschaftslehre adın alıncaya kadar, bu bilim kolu çeşitli adlar almıştır. Konusunun da mahiyet itiba- riyle değişmesiyle paralel olarak bu bilim kolu ticaret ilmi, ticari işletmeler bilgisi, hususî ekonomi bilimi isimlerini almıştır.

Alman işletme ekonomisinin kökieri ilim ve ögretim kurum»larından aramak icap eder. Işletme ekonomisinin gelişim tarihinde Alman işletme ekonomisi ilmi üç kökten kuvvêt alarak meydana gelmiştir. Bunlar :

1 - Ticari bilgiler.

2 - Kameral bilgiler.

3 - Teknik ve ekonomik organizasyon bilgileri.

1) İlkönce ve en fazla Yüksek ticaret okullarında tedvin edildiği için bilgimizin ilk malzemesini bu okullarda okutulan ticaret bilgisi, ticaret teknikli konularından almıştır.

2) İşletme ekonomisinin ikinci ana kökü 18 inci asırda Aimanyada tedris edilen Kameralwissenschaften'dir. Bu devirde Merkantilist fikirlerden mülhem olan devlet, ekonomi sahasına müdahale ediyor, bazı işletmeleri bizzat üzerine alıordu. Varidat temini maksadiyle çalıştırdığı ziraat ve orman isşlctmelerinde kullanacăgı memurların bu kameral ilimlerle mïcehhez olmalarını istiyordu.

18 inci asın Alman devleti, bizzat işlettiği ışletmelerine yarayacak tedbirler yanında, umumî ekonomiyi de teşvik etmekten de geri kalmiyordu. 
Devlet işletmeleringde çalışacak olan elemanlara ögretilen bu kameral ilimler (devlet ilimleri) üç esas kısımdan terekküp ediyordu: Ekonomi siyaseti (polisî bilgiler), Hususî ekonomi (ekonomi işletmeleri bilgisi) ve Finans yani maliye ilmi (vergi ve bütçe bilgisi).

19 uncu asırda ticaret ve sanayi hayati inkişaf etmiş, devletin ekonomik sahaya müdahalesi azalmıştı. Devlet elindeki işletmeleri hususî teşebbüslere kiraya vermeği veya satmağı dahạ elverişli buluyordu.

Böyle bir siyaset neticesinde, devletin kendi memurlarına ekonomi ilimleri, bilhassa hususî ekonomi bilgileri ögretmek hususunda arzusu azaldi. Esasen bu tarihlerde Alman Universitesinde Roma hukuku tedrisatına daha fazla yer veriliyordu. Bu suretledir ki, 19 uncu asrın başından itibaren Alman üniversitelerinden çıan ve idare hayatına atılan gençler hukuk tahsili görmekle iktifa ediyorlard.

Bilhassa Ingiliz ekonomisi ilminín şiddetli tesiri altında eski kameral ilimlerin yerine millet ekonomisi (Economie politiquẹ). kaim oldu. Kameral ilimlerin yukarıda saydığimiz üç disiplininden yalntz Maliye ilmi, evvelce ihtiva ettiợi vergi ve bütçe kısmina "devletin hususî emlâk ve işletmelerine ait" bahsini de ilâve ederek mevkiini muhafaza edebildi.

Hususî ekonomi bilgisi ise, millet ekonomisi şekline bựrünerek ekonomiyi hususî surette değil, umumî bir surette cemiyet bakımindan tetkik etmege koyuldu ve ekonomik liberalizmden aldığı ilhamın tesiriyle hayli inkişaf etti; devlet idaresinin esasiarından ve dahilî siyasetinden bahseden polisî bilgiler $\mathrm{kısmı} \mathrm{da}$ esasen pek ilmî sistem arzedemeyen malzemesini idarî hukuka terkederek ortadan kalktı.

Kameralist bilgilerin parçalanması ve yerlerini millet okonomisi ilmine terketmeleri, müesseselerin kâr gayesine ve ticarî usullere göre idare edilmesini öğreten hususî ekonomi (Privatökonomik) bilgisi Universitelerden ve Kameralhochschule adını, taşıyan Alman mülkiye mekteplerinden uzaklaşmiştr; hususî ekonomi bilgisinin bakiyesini bu defa ticaret mektepleri kabul ederek mevzuu cemiyet ekonomiși, hukuk bilgisi ve ticaret, tekniğine ait malûmatın bir halitasını teşkil eden ticaret bilgisine (Handelslehre) ilâve ederek okutmuşlạrdır. Herşeyden bahseden bu bilgi ilmî 
karakterini kaybetmiş bulunuyyordu. İletme ekonomisinin tekrar ilmî bir mahiyet kesbetmesi 19 uncu asrın başinda Yüksek Ticaret Mekteplerinin tesisi ile başlar (1898).

Bu müesseselerde yeniden işlenmeğe başlanan işletme ekonomisi "Ticarî ilimler" adını taşıyor; 1912 senesinden sonra mevzuu ticarî müesseselerin bilgisinden maada sınaî müesseseler ve bankalara ait malûmatın girdiği de nazarı itibara ahnarak hususî ekonomi bilgisi ismi kondu.

Yüksek ticaret mekteplerinde inkişaf eden bu disiplin bir çok yüksek mekteplerden maada Universitenin programlarına da ithal edilmege başlandı. Fakat, shususî ekonomi’ ismi de uzun zaman yer tutmadı ve büyük harpten sonra yerini bugün kullandığımız * Işletme ekonomisine * verdi.

Yeniden ortaya çıkan bu ilme işletme ekonomisi bilgisi denmesinin asıl sebebi, ilmin eski ismi olan hususî ekonominin mevzuu tam ifade edememesinden dolayıdır. Çünkü, hususî ekonomi deyince, sırf hususî̀ işletmelerin bünyelerinden, ihtiyaçlarından, münasebetlerinden' ve sair hususlarından bahseden bir bilgi hatıra gelmektedir. Halbuki, son zamanlarda kamusal işletmelerde de, ticarî ve ekonomik gayeler ve işletme tarzlari tetkik edilmeğe başlanmıştır. İ̧letme ekonomisi tabiri, gerek hususi ekonomiye ait işletmeleri, gerek devletin ve sair amme teşebbüslerinin işletmelerini ihtiva ettiğinden «hususî ekonomi» tabirine, tercih edildi ve her tarafta yer tuttu. Kaldı ki, hususî ekonomi deyince, hususî kapitalist ekonomiler de hatıragelmektedir. Halbuki, işletme ekonomisi ilminin biraz sonra izah edeceğimiz mevzuu ve çerçivesi daha geniş, rengi daha bitaraftrr.

3) İșletme ekonominin politik ve ekonomik ilimlere dayanan birinci kökü ile ticaret bilgilerine dayanan $i k i n c i$ kökünden bahsetmiştik. Bu ilmi gıdalandıran üçüncü bir kök de, teknik ve eko. nomik organizasyon bilgilerine dayananıdır. Bilhassa, bu kökten kuvvet alan ve gelişen bir işletme ekonomisine Birleşik Amerikada rastllyoruz. Taylor ve onu takip eden mühendislerin endüstri sahasında meşgul oldukları ellmî işletme tarzı (Scientific menagement) sanayide rasyonalizasyon hareketleri, iş organizasyonu pratik sahada bulunup nazarî bir șekilde işlenen bir ilim haline gelmiştir. Bu münasebetle bilhassa, Amerika ile Almanya arasındaki bir hususiyete işaret etmek münasip olur. Almanya'da ilim 
daha evvel inkişaf ediyor ve pratik hayata müessir oluyor. Birleşik Amerikada daha ziyade tatbikat kendini gösteriyor. flim bundan ilham alıyor ve amelî meseleleri nazarî bịr şekilde işliyor.

Isşte, bu üç mühim kökten gıdalandıktan ve kuvvetli müelliflerin elinde yuơgurulduktan sonra karşımıza müstakil mevzulu bir ilim olarak ç̧ıan işletme ekonkmisi bu suretle tekevvün etmiştir. Fakat, bütün bu inkişafına rằ̛men ilmimizin bir çok eksik tarafları olmał̆a mecburdur: Yeknasaklık gösteren bir ką̧ eksik cihetin ikmaliyle kemale gelecektir. Bu ise bir kaç senelik bir meseledir. Bu hususta çalışan müellifler iki muhtelif noktadan hareket etmektedirler.

Işletme ekonomistlerinin bir kısmı, bu bilimin kurucularından Schmalenbach'in tuttư̆u yoldan yürüyerek ilmî yapıyı aşă̆ıdan yukarıya doğru ikmale çalışmaktadirlar. Yani, evvelâ muhtelif meseleler üzerinde durmakta ve münferit meseleler üzerinde kâfi derecede vuzuh kesbetmekle iktifa ediyorlar. Münferit bilgilere istinat ederek yükselecek ilmî bir sistemin kurulmasını ve bu üst yapıyı geçecek umumî ve nazarî bir temelin teșisini daha sonraya bırakıyorlar. Bunlara nazaran tam bir işletme ekonomisinin geniş bir sistemini ancak zaman gösterecektir. Bu ilim organik bir oluş devresi geçirdikten sonra kemale gelecektir.

Işletme, ekonomistlerinin diğer bir kolu,Nicklish, Schaer ve son zamanlarda Werner'in takip ettiği yollar tam ve nihaî bir sistem veremeyeceklerini teslim etmekle beraber bu müellifler münferit meselelerin tetkikiyle iktifa etmiyor, ilme derli toplu bir istikamet, bir sistem vermeğe çalışıyorlar. Münferit problemler işlendikçe, vuzuh peyda ettikçe, işletme ekonomisine mensubiyetini isbat ettikçe sistem tamamlanacaktır. Bu, Almanyadaki vaziyet! Birleşik Amerikadaki mesai tarzı da tam ve yeknasak bir sistem arzetmekten uzaktır.

Görülüyor ki işletme ekonomisi ilminin yapısı tamamen bitmiş. değildir. Bu mevzu girecek malzemenin çoklư̆u ve mürekkepliğine rağmen binanın bir kaç eksik tarafı vardır. Buna mukabil işletme ekonomisine ait tetkikler her gün artmakta ve bu ilmin sür'atle intişar ettiğini tebşir etmektedir.

Ingiltere : Bir çok meselelerde olduğu gibi işletme ekonomisi mevzuiunda muhafazakâr davranmıștır. «Business Economics» şeklinde ilim diline girmiş olan Ingiliz işletme ekonomisi ancak son 
senelerde inkişafa başlamıştır. Mamafih Ingilterede tedvin edilen - Cemiyet ekonomisi ilminde teşebbüs bahsinden maada para ve sermaye piyasalarına, iş piyasalarına, emtia piyasalarma, daha fazla yer verilmektedir. Bunun tipik bir misalini "Stephenson, un *The Principles of business economics" adlı kitabıdır. Hülâseten denilebilir ki Ingiliz ekonomi ilminde cemiyet ekonomisi ile ișletme ekonomisi memzuq bir halde tedvin edilmektedir.

Birleşik Amerika: Bu memlekette son 30 senedenberi işletme ekonomisi bir hayli inkişaf etmiştir. Birleşik Amerikada bu mevzua ait münferit mevzular tetkik edilmiştir, ezcümle silmî iş̧letme usulleri’ işletme hesapları eişletme istatistiki ’ iş psikolojisi psikoteknik mevzuları üzerinde enteresan tetkikler yapılmıştır. Amerikan işletme ekonomisi Alman işletme ekononisinin aksine olarak tatbikattan mülhem olmuştur. Nazarî işletme ekonomisine ait kitaplarn başında profesör Clark'n "The Economics of Overteal costs" u gelmektektedir. Son senelerin işletme ekanomisi - literatüründa bilhassa işletme bütçeleri «Planing» mevzularına çok fazla önem verilmektedir.

Diğgr memieketlerden: Işletme ekonomisine önem verenlerden Sovyet Rusyayı, Italyayı ve Japonyayı zikketmek icap etmektedir.

Fransa'da: Fransizca da, Almancanın Betribe ve Türkçenin «işletme"sine tekabül eden bir kelime yoktur. Bazen işletmeye mukabil kulianılan "Exploitation* kelimesi daha ziyade «istismar * mânasina gelmektedir.

Işletme ekonomisi sistematik bir ilim olarak tedris edilmemektedir. Uzun zaman yüksek mekteplerde Savary nin "Le parfait négociant ad̆h kitabı bu mevzua en yaklaşmış eserlerdendi. Diğer taraftan muhasebeye dair bir hayli kitaplar mevcuttur. Işletme ekononisi ilmine bir dereceye kadar yaklaşmak itibariyle Fayolte'nin umumî ve sınaî idareye (Administration générale et endustrielle) dair yazdığı eserdir. Mücerret bir mahiyet arzetmekle beraber bu kitap Türkçe dahil olmak üzere bir çok dillere tercüme edilmiştir.

Son senelerde bilhassa Paris Yüksek Ticaret Mektebinde Gouvernement et administration des entreprises ismi altinda bazı derslerde işletme ekonomisine ait bazı problemler tetkik olunmaktadir. 
Türkiye'de: Işletme ekonomïsi bilgisinin memleketimizin tedrisat sistemine giriş tarihini 1933 yıl ile başlabilıriz.

Hemen aynı senede Istanbul Üniversitesi lktisat ve Içctimaiyat Enstitüsünde, Istanbul Yüksek lktisat ve Ticaret mektebinde genel işletme ekonomisi, Ankara Yüksek. Ziraat Enstitüsünde ziraî işletme bilgisi, Ankara Ticaret Lisesinde işletme bilgisi adlarımı taşıyan dersler okutulmağa başlanmışıtı. Siyasal Bilgiler okuluna bu ders 1939/40 ders yilinda okutulmağa başlanmıştır.

İşletme ekonomisine dair ilk yazzlar 1931 yulinda clktisadî ilim şubelerinden işletme iktisadı ` adını taşıyan bir broşürümüzle başIamı̣s, buna profesör Zühtü İnan, Ismet Alkan, Alfred Isaac'ın 1937 senesinde bu konuda yazdıklan ders kitapları bu sahada intişar etmiş ilk eserlerdır.

\section{II. İ̧letme Ekonomisì Billimi ve Tatbiki Ekonomi}

İsletme ekonomisi biliminin muhtelif mesleklere ve bu meyanda Tatbiki ekonomiye neden yarıyabilecĕ̛ini gösterebilmek için, bu ilmin incelediğ̣i, belli başı problemleri kısaca sıralamak faydah olur. limin genel ve teorik kısminda temas olunan konular şunlardır:

Teşebbüs şekillerinin mahiyeti, işletmelerin kurulus yerleri ve optimal cesametleri, istihsal kudretleri, iştigal dereceleri, organizasyon şekilleri ve prensipleri, rasyonalizasyon, modern idare tarzları ve usulleri; işletmelerde insan unsuru, sermaye unsuru; $\ddot{o z}$ ve yabancı sermayelerin tedariki, kullanılması ve nemaland!rilması, işletmelerde hesap işleri bu meyanda muhasebe prensipleri, maliyet masraflarımn tetkiki, is proğramı ve işletme bütçeleri, işletme istatistikleri.

İsletmede derri daim: Tedarik, istihsal, imalàt, stok ve sürüm hareketleri, işletme içinde ve dışında kıymet hareketleri, kıymet takdiri prensipleri, amortisman, ihtiyat ve karş̧lık konuları.

İşletme neticeleri, muhtelif mahiyette kârlar, rantabilité ve productivité meseleleri ve nihayet işletmelerin tetkik, kontrol, teftiş ve murakabaları gibi meselelerdir.

Burada ancak en önemlilerine temasla geçtiğimiz bu'konu* ların birçok iş ve meslekleri yakından ilgilendirdiğine şüphe yoktur. Bu konulardan da görüleceği veçhile işletme ekonomisi bilimi ampirizm'in yerine rasyonalizmi ikame eder bir disiplindir. 


\section{Tatbiki Ekonomi siyasetinde igletme ekonomisinin önemi}

Tatbikî iktisat veya iktisat siyaseti dediğimiz ekonomiyi; 1) ziraat ekonomisi, 2) sanayi ekonomisi. 3) ulaştırma ekonomisi, 4) ticaret ekonomisi diye dört ana bölüme ayırarak burada işletme ekonomisi ne derece tatbik edildiø̆ini görelim. Teoride nasil genel ekonomi bilimine tekabül etmek üzere bir genel işletme ekonomisi tekevvün etmiş ise, tatbikî ekonominin yukarıda isimlerini yazdığımız kollarına mukabil, bir ziraat işletme ekonomisi, bir sanayi işletme ekonomisi, bir münakalât işletme ekonomisi, ve bir ticaret işletme ekonomisi meydana gelmiştir. Hattâ tatbikî ekonominin özel bazı şubeleri işletme ekonomisini büsbütün benimsiyerek banka işletme ekonomisi sigorta işletme ekonomisi gibi konuların sı̣f işletmecilik bakımından incelemeleri yapılmıştır.

\section{II. Işletme ekonomisi ve ekonomi siyasetleri :}

Diger taraftan devletin ve belediyelerin ekorom: siyasetlerinin tedvinde ve tatbikatında işletme ekonomịinden azamî derecede istifade edilmiştir. Maliye tatbikatında;a işıtetme exonomisinden faydalanmamak mümkün değildir. Vergi tâthindan evvel türlü işlétmelerin faaliyetlerini, sermayelerinn devirlerini, hakikî kârların. durumunu tayin etmek, takdiri kiymet, amortisman, ihtiyat, karşıltkların mahiyetlerine nüfuz etmek hususunda işletme ekonomisi bilimi yepyeni ufuklar açmaktadir.

Ziraat siyasetinde meselâ istihsal masiafların hesaplamada, sanayi siyasetinde, sınâ̂ işletmelerin maliyetihi tayinde, sanayie verileeek optimal cesametlerinde, bazı sanayi gruplanını himayesinde, ücret ta:ifelerinin tasdikinde, münakâlât politikasında vé nihayet fiat politikasına müteallik tabirleriyle sair sahalarında ana konularına yukarıda işaret ettiợimiz işlețme ekonomisinden istifade etmemek kabil de grildir.

Hülâsa; işletme ekonomisi ilmî, tatbikî cemiyet bilimleri arasinda, maizemesini hayattan alan, ve araștırmalar neticesinde elde ettiği bilgileri, büyük ölçüde tatbikata tahsis eden bir disiplindir.

Tatbikatla bu kadar ilgisi olmakla beraber, işletme ekonomisi bilimi nazarî bilimlerin usullerini gerçek; olanlara tatbik suretiyle, bunları azamî derecede değerlendirmeğte muvaffak olmuştur. 


\section{Işletme ekonomisi biliminin hukukçuya faydası:}

lkktisat işlerinin müstakil bir ihtisas haline geldiği ve müsta* kil bir tahsil istilzam ettirdiłi son zamanlarda bile, deviet memuru kadar, serbest sahada çalışan hukukçunun da iktisadî düşüncesine, teşkilât ve hesap işleriyle az çôk meşgul olmasına ihtiyacı vardır,

Idare adami olarak türlü bakanlhklarda ve kurumlarda çalı* şacak grenç elemanlarm rasyonel usullerle çalışabilmeleri, işletme ekonomisi ilminden alacakları ilham ve edinecekleri bilgi ile kolaylıkla mümkün olabilir.

Adliye sahasında çalışıp ticari muameleler üzerinde hüküm verecek olan hukukcuların ise, hesap ve maliyet işleriyle takdiri kıymet prensipleri gibi konuları hakkında esaslı malumatları olmaları aşikârdır.

Serbest sahada avukat ve hukuk müşaviri olarak çalışan hukukcuların şahıs ve şirket halinde faaliyette bulunan teşebbüs ve ișletmelerin kuruluş, işleyiş. iflâs ve sair safhalarında tahaddüs eden meseleler, ticaret hukukunun borçlar hukukunun ihtiva ettiŏi konular hep işletme ekonomisinin kavradığı malzemelerdir.

Velhassl hukukçuya, ötedenberi hukuk fakültelerinde okutulan nazarî iktisat ilmi kadar, belki de ondan fazla olarak, işletme ekonomisi ilmine de ihtiyaç vardır. 